\title{
Impact of Endogenous Risk Factors on Risk Cost in PPP Projects in Saudi Arabia
}

\author{
Yahya Alfraidi \\ Architecture Engineering Department \\ University of Hail \\ Hail, Saudi Arabia \\ y.alfraidi@uoh.edu.sa
}

\author{
Mohamed Hssan Hassan Abdelhafez \\ Architecture Engineering Department, University of \\ Hail, Hail, Saudi Arabia and Architecture Engineering \\ Department, University of Aswan, Aswan, Egypt \\ mo.abdelhafez@uoh.edu.sa
}

\author{
Saleh Mohammed Alzahrani \\ Civil Engineering Department \\ University of Business \& Technology \\ Jeddah, Saudi Arabia \\ s.alzahrani@ubt.edu.sa \\ Halim Boussabaine \\ Faculty of Business and Law \\ The British University in Dubai \\ Dubai, United Arab Emirates \\ halim@buid.ac.ae
}

\begin{abstract}
The formation of the Public-Private Partnership (PPP) contracts is based on the grounds that the construction, progress, operation, and investment of a project must be allocated to a private organization under a contract. The risks associated with PPP projects are usually associated with resource improvement and development as well as the long-term operation of the project. It is known that cost and time overruns are among the obvious risks faced by a project during the development phase. Cost and time overruns are major sources of monetary risk. The risk and its impact may vary at different phases during the life cycle of a PPP project. In traditional procurement, all of the monetary risks are covered by the public sector. Most of the projects delivered under traditional procurement involve a price confirmation to indicate standard cost risks. This paper aims to investigate the impact of endogenous factors on budget overrun in PPP projects in Saudi Arabia. The paper briefly illustrates the content regarding the PPP risk evaluating systems and explains the association between risk occurrences and cost overrun in the Kingdom of Saudi Arabia (KSA). The paper concludes with recommendations for future research.
\end{abstract}

Keywords-Public Private Partnership (PPP); risk; risk pricing; System Dynamics (SD)

\section{INTRODUCTION}

Developing countries usually prioritize investing in construction development. Mega construction projects need huge financial and human resources. Building complex engineering projects requires a prominent level of expertise, and well-managed teams with sufficient monetary resources, which are often beyond the capability of a single contractor [1]. The public and the private sector are concerned about the pricing risks associated with PPP projects. Many projects depicted cost and time overruns and project failure leading to unexpected results. Risk management's cost may affect risk allocation. The main challenges faced by organization managers involve dealing with the uncertainty and the intricacy of PPP projects and inaccurate cost incorporation during the decision-making phase. Only a few organizations incorporate the risk probability in their strategy [2]. The shortcomings of the management in terms of their processes and functionality are evident from the complexity associated with projects which indicate the failure of managers to handle the vital characteristics of major projects. The understanding of managers concerning the emergent characteristics is determined by their perceptions leading to loss of insight [3].

Cost overrun usually results from inappropriate management of risks and may be prevented if each party to the contract displays proper understanding of risk responsibilities, conditions of risk, risk preferences, and risk management expertise. The party that displays the best potential and expertise of risk management must be allocated with the management responsibility $[4,5]$. As per [6], this allocation of risk to the competent party is imperative for the execution of construction projects within the specified cost where the owner is responsible for the quality, progress, and the costs of the project [7]. All the risks are not allocated to the contractor in case of traditional procurement. Conversely, PPP projects are known to exhibit more certainty in terms of cost and time. However, it is not necessary to allocate all risks to the private sector in order to accomplish value for money, the risks are rather allocated to the party that is most efficient in risk management [8]. The involvement of the private sector in public sector projects has been done in the past, however, the scope and extent of the concept witnessed drastic development and progress in the past three decades. The private-public cooperation existed in various forms in various parts of the world depending upon the regions' law systems and economic conditions. However, the main motive behind the cooperation of private and public sectors was the allocation of long-term public project risks to the private sector which is usually more capable of handling these risks. The interconnection between the value for money and risk allocation is one of the most

Corresponding author: Yahya Alfraidi 
significant features of PPP projects [9]. The risk allocation determines the real worth of PPPs whereas the prices used for compensating the contract costs are too high in project life cycle techniques [10]. The precise measurement and assessment of risk cost require a reasonable level of expertise and competency on the part of the risk analyst. In the case of the absence of comprehension and information regarding the consequences of unexpected events and the magnitude of these consequences, analysts require theoretical models to predict the outcome prices in case of unexpected events. Therefore, the risk analyst must have a comprehension of the appropriate methods for obtaining precise information to enable them to allocate risk in an appropriate manner and make the project successful [11]. The concept of project risk analysis exists for years, however, concerning the construction sector, the theory of risk pricing under uncertainty is not yet fully developed. The significance of this concept is evident from the fact that data obtained from qualitative and quantitative studies serve as the basis of a majority of risk pricing decisions in PPP projects [12]. Not much verification was found in support of the government's claim that the allocation of risk is the cause of additional PPP cost [13]. Practically, there is no research on investigating the association between risk allocation and construction cost. This study fills this gap and investigates the association between risk allocation and risk cost involved in a PPP project executed in KSA.

\section{RESEARCH METHODOLOGY}

Various phases are involved in the research method as shown in Figure 1. The first phase presents the literature reviews of the concept in order to comprehend the risk factors that are likely to have an impact on the construction cost unit associated with a PPP project. This technique corresponds to the existing research regarding this concept. Consequently, a list of risk factors has been generated and more risk factors were incorporated into the existing list. This was followed by the recognition of suitable risk descriptions based on project management viewpoints regarding the PPP projects. A survey questionnaire was distributed among PPP experts to obtain their views regarding the detection of risks, assessment of risk impact, and risk pricing associated with PPP projects. The experts participating in the survey were requested to suggest the most appropriate risk allocation for the risk factors based on the extent of risk cost. The data obtained from the answered questionnaires were analyzed and converted into Microsoft Excel and Statistical Package for Social Science (SPSS) format to obtain numerical data for the research. Experimental analysis was conducted to determine the grading of the extent of the impact of the risk associated with PPP projects on risk cost by survey respondents. The outcomes obtained from the analysis were stated in terms of risk occurrence. The impact of risk is estimated by making use of the data regarding the probability of risk occurrence and the intensity of its impact [2]. In other words, if the probability of risk occurrence is represented by $P$ and the intensity of the impact of this risk on the project is represented by $I$ [4], then the expected risk effect value or $E V$ would be given as follows:

$$
E V=P . I
$$

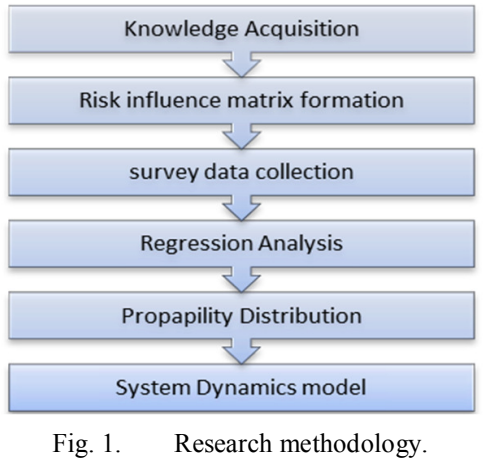

The anticipated impacts of risks were represented in a 1 to 25 scale. The data collection is stabilized between 0 and 1 . This was followed by the development of multiple regression equations based on these values.

\section{ENDOGENOUS RISK FACTORS}

Even though the field of risk management aims to the mitigation of risk impact in construction projects, there is still a need of a systematic approach in the modeling of the impact of the risk factors into the construction cost. Moreover, this needs to be expanded in the modeling of the interactions and the interdependency of the endogenous risk factors into the construction cost of certain types of projects such as PPP projects, which are tackled in this research paper. The risk factors of PPP projects have been investigated in [14-16], especially the factors that are influencing cost overrun, project termination, and time delay. These three factors are the drivers of increased cost in construction projects. As described above, a questionnaire survey was conducted to provide a general review of the current pricing risk practice in KSA. The main aim of this survey was to investigate the impact of risk on cost unit and the best risk allocation in PPP projects. The impact of risk factors will be assessed based on the respondent perspectives and experience. Descriptive analysis for endogenous risk category is mapped into 4 sub-categories: project selection risks, project finance risks, construction risks, and related risks. Every sub-category consists of some factors, the top-ranked factors are chosen to be studied in the present research, which include: public resistance towards projects, uncompetitive tender, financial resources, elevated financial cost, elevated bidding cost, impediment in allowance payment, impediment in financial closure, construction time impediment, intricacy of design \& construction, flaws in design, construction technology risks, quality risks, inadequate dedication from the public/private sector, inadequate distribution of accountability and risk, inconsistency between project parties, and strikes. On the other hand, low ranked factors such as: level of demand for the project, land acquisition, competition risk, inaccurate estimates, financial attraction of project to investors, lack of creditworthiness, inability to service debt, lack of government guarantees, material availability, labor availability, poor quality of workmanship, the default of sub-contractors or suppliers, contractual risk, contractor failure, different working methods between partners, inadequate experience in PPP, organization and coordination risks, inadequate negotiation period before 
initiation, and cultural differences between main stakeholders, were neglected.

\section{MODELING ENDOGENOUS RISKS IMPACT}

The efficiency of construction, management and engineering projects can be assessed with the help of regression modeling $[17,18]$. The basic principle behind the regression modeling technique is that the dependent variable $Y$ is changed as a result of the change in the independent variable $X$. Multiple regression models were used for the forecast of the dependent variable (construction cost overrun) and the independent variables (endogenous risk factors associated with the construction cost overrun):

$$
Y=\beta_{0}+\sum_{i=0}^{n} R p_{i} \beta_{i}+\varepsilon_{i}
$$

In (2), $Y$ represents the value of a dependent variable, $\beta_{0}$ represents the constant or regression coefficient, $R p_{i}$ represents the value of independent variables, and $\varepsilon_{i}$ represents a constant term or noise.

Various combinations of independent variables (the endogenous risk factors associated with the construction cost overrun) were analyzed. The multi-linear models aim to allocate the extent of risk cost by outlining risk into the alternating variable. The model explained the association between various risk factors. The regression models help experts in conducting risk price analysis using theoretical methods. This implies that every independent variable will be considered as a theoretical variable integrated with a probability distribution practically obtained from the study data. In order to practically outline the risk impact of independent variables, the multiple regression equation was devised as:

$$
Y_{\text {Endogenous }}=\mathrm{a}+R p_{28} \beta_{28}+R p_{29} \beta_{29}+R p_{33} \beta_{33}+
$$
$R p_{35} \beta_{35}+R p_{36} \beta_{36}+R p_{37} \beta_{37}+R p_{40} \beta_{40}+R p_{45} \beta_{45}+$ $R p_{50} \beta_{50}+R p_{51} \beta_{51}+R p_{53} \beta_{53}+R p_{56} \beta_{56}+R p_{59} \beta_{59}+$ $R p_{61} \beta_{61}+R p_{63} \beta_{63}+R p_{64} \beta_{64}+\alpha$

In the above equation, a represents the constant or regression coefficient and $\alpha$ represents the constant term or noise, $Y$ represents the endogenous risk impact, and $R p$ represents the factors shown in Table I.

TABLE I. ENDOGENOUS RISK FACTORS MODEL

\begin{tabular}{|c|c|}
\hline Factor & Endogenous risk factor \\
\hline $\boldsymbol{R} p_{28}$ & Public resistance towards projects \\
\hline $\boldsymbol{R} \boldsymbol{p}_{29}$ & Uncompetitive tender \\
\hline $\boldsymbol{R} \boldsymbol{p}_{33}$ & Financial resources \\
\hline $\boldsymbol{R} p_{35}$ & Elevated financial cost \\
\hline $\boldsymbol{R} p_{36}$ & Elevated bidding costs \\
\hline $\boldsymbol{R} \boldsymbol{p}_{37}$ & Impediment in allowance payment \\
\hline $\boldsymbol{R} \boldsymbol{p}_{40}$ & Impediment in financial closure \\
\hline $\boldsymbol{R} \boldsymbol{p}_{45}$ & Construction time impediment \\
\hline $\boldsymbol{R} \boldsymbol{p}_{50}$ & Intricacy of design and construction \\
\hline $\boldsymbol{R} \boldsymbol{p}_{51}$ & Flaws in design \\
\hline $\boldsymbol{R} \boldsymbol{p}_{53}$ & Construction technology risks \\
\hline $\boldsymbol{R} \boldsymbol{p}_{56}$ & Quality risks \\
\hline $\boldsymbol{R} \boldsymbol{p}_{59}$ & Inadequate dedication from public/private sector \\
\hline $\boldsymbol{R} \boldsymbol{p}_{61}$ & Inadequate distribution of accountability and risk \\
\hline $\boldsymbol{R} \boldsymbol{p}_{63}$ & Inconsistency between project parties \\
\hline $\boldsymbol{R} \boldsymbol{p}_{64}$ & Strikes \\
\hline
\end{tabular}

The measurement of project risks was carried out using construction cost overruns. There are several exogenous risk independent variables and the construction cost overrun is the dependent variable. If the $Y$ value increases, it is assumed that the risk price has increased along with construction risks. Hence, there is a price that a stakeholder would charge to bear all risks. Furthermore, it may also be suggested that if the $Y$ value increases, the exogenous risks are proved to be significant. The risk bearer can bear all risks if the suitable price has been identified.

\section{RESULTS}

With the help of multiple regression, the proxy variable (dependent variable) value can be predicted. The value used is that of the endogenous risk factors (independent variables). Tables II and III show the multiple regression analysis outputs extracted from the SPSS software. These results indicate that there is an effect of almost all endogenous risk factors since their p-values are below 0.05 . On the other hand, the common alpha level is 0.05 and the $\mathrm{p}$-value for $R P_{28}(0.054)$ and $R P_{29}$ $(0.052)$ are a little higher, which is why it can be stated that they are not statistically significant. These $p$ values do not fit the range which is relevant for the current research assumption part of the equation. For each of the risk impact events, the coefficient magnitude can be observed in Table I. The highest level of positive effect upon cost overrun is observed in Table II for $R P_{45}$. It can also be observed that there are mostly negative endogenous risk event impact coefficients. Hence, it is stated that low-cost overruns would occur if there is a high influence of risk events. The generated model statistics are presented in Table III. It is observed that the endogenous multiple regression model includes 16 risk impact events with $R^{2}=0.902$ and $\mathrm{p}<0.05$. Therefore, the results indicate that in both models, significant variations are present within the data set of the risk impact events.

\begin{tabular}{|c|c|c|c|c|c|}
\hline \multirow[t]{2}{*}{ Factor } & \multicolumn{2}{|c|}{$\begin{array}{c}\text { Unstandardized } \\
\text { coefficients }\end{array}$} & \multirow{2}{*}{\begin{tabular}{|c|}
$\begin{array}{c}\text { Standardized } \\
\text { coefficients }\end{array}$ \\
Beta \\
\end{tabular}} & \multirow[t]{2}{*}{$\mathbf{t}$} & \multirow[t]{2}{*}{ Sig. } \\
\hline & B & Std. error & & & \\
\hline (Constant) & 0.161 & 0.036 & & 4.463 & 0.000 \\
\hline$R p_{28}$ & -0.145 & 0.074 & -0.123 & -1.969 & 0.054 \\
\hline $\boldsymbol{R} p_{29}$ & 0.218 & 0.110 & 0.135 & 1.993 & 0.052 \\
\hline$R p_{33}$ & -0.169 & 0.063 & -0.170 & -2.679 & 0.010 \\
\hline$R p_{35}$ & -0.433 & 0.069 & -0.385 & -6.293 & 0.000 \\
\hline$R p_{36}$ & 0.378 & 0.078 & 0.290 & 4.863 & 0.000 \\
\hline$R p_{37}$ & 0.192 & 0.063 & 0.147 & 3.028 & 0.004 \\
\hline$R p_{40}$ & -0.311 & 0.104 & -0.183 & -2.994 & 0.004 \\
\hline$R p_{45}$ & 0.746 & 0.067 & 0.693 & 11.151 & 0.000 \\
\hline$R p_{50}$ & 0.414 & 0.083 & 0.381 & 4.968 & 0.000 \\
\hline$R p_{51}$ & -0.173 & 0.074 & -0.175 & -2.347 & 0.023 \\
\hline$R p_{53}$ & -0.302 & 0.088 & -0.220 & -3.440 & 0.001 \\
\hline$R p_{56}$ & 0.640 & 0.125 & 0.440 & 5.140 & 0.000 \\
\hline$R p_{59}$ & -0.317 & 0.098 & -0.218 & -3.242 & 0.002 \\
\hline$R p_{61}$ & -0.224 & 0.077 & -0.193 & -2.907 & 0.005 \\
\hline$R p_{63}$ & 0.339 & 0.086 & 0.242 & 3.933 & 0.000 \\
\hline$R p_{64}$ & -0.337 & 0.125 & -0.206 & -2.698 & 0.009 \\
\hline
\end{tabular}

TABLE II. ENDOGENOUS MODEL REGRESSION RESULT

Table III indicates that the $\mathrm{p}$-value is lower than $5 \%$, and the model explains quite a strong supposition against the null hypothesis since $\mathrm{p} \leq 1 \%$. 
TABLE III. INTEGRATED MODEL REGRESSION

\begin{tabular}{|c|c|c|c|c|c|c|c|}
\hline \multirow[b]{2}{*}{$\mathbf{R}$} & \multirow[b]{2}{*}{$\mathbf{R}^{2}$} & \multirow{2}{*}{$\begin{array}{l}\text { Std. error of the } \\
\text { estimate }\end{array}$} & \multicolumn{5}{|c|}{ Change Statistics } \\
\hline & & & $\mathbf{R}^{2}$ change & F change & df1 & df2 & $\begin{array}{l}\text { Sig. F } \\
\text { change }\end{array}$ \\
\hline 0.962 & 0.902 & 0.0621433 & 2.653 & 39.741 & 16 & 51 & 0.000 \\
\hline
\end{tabular}

The central alterations of the dependent variable with the independent variable for each unit of change are represented by its regression coefficient. The rest of the model predictors have been kept constant. Within a flawless environment, the predictors can be measured using the same reliability levels. Hence, using the unstandardized coefficients, the predictor variable weights present in Table II were applied upon (3):

$$
Y_{\text {Endogenous }}=0.161-0.145 * R p_{28}+0.218 * R p_{29}-0.169 *
$$
$R p_{33}-0.433 * R p_{35}+0.378 * R p_{36}+0.192 * R p_{37}-0.311 * R p_{40}+0.7$ $46 * R p_{45}+0.414 * R p_{50}-0.173 * R p_{51}-0.302 * R p_{53}+0.640 *$ $R p_{56}-0.317 * R p_{59}-0.224 * R p_{61}+0.339 * R p_{63}-0.337 * R p_{64}+$ 0.036

$$
0 \geq Y \geq 1
$$

The approximations for the theoretical and observed data and the reference line can both be seen in the exogenous risk impact event P-P plot. The reference line and the observed data are quite close which indicates that the observed data and the derived equations are extracted from the same population and similar distributions (Figure 2).

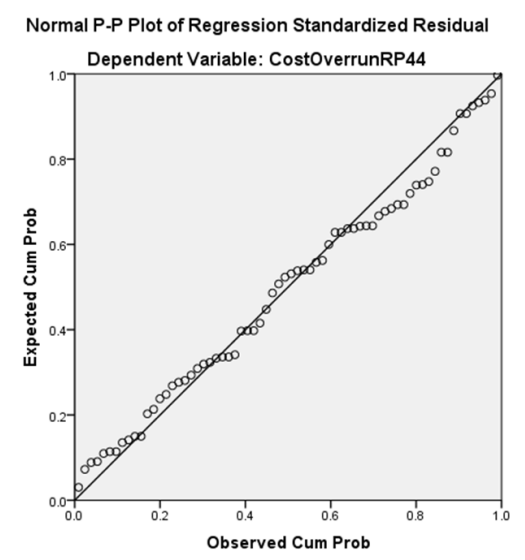

Fig. 2. Endogenous risks P-P plot.

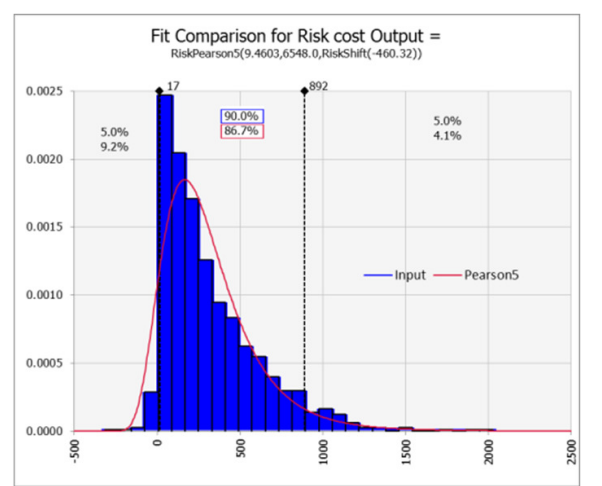

Fig. 3. Endogenous model - risk cost output - probability density/ cumulative overlay.

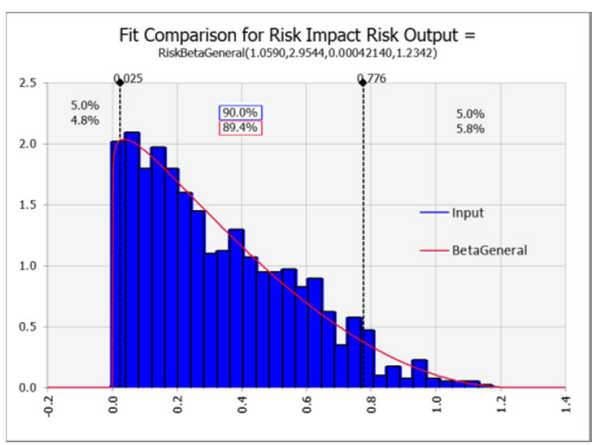

Fig. 4. Endogenous model - risk impact output - probability density / cumulative overlay

\section{DISCUSSION}

With the help of the literature review, we have been able to extract the risk influence upon the PPP projects in a systematic manner. Using a theoretical base, the classification has been carried out in terms of risk type, risk source, and project environment (internal or external). Several variables influence the project-specific risk events, including project company effectiveness, project stakeholder relationships, and many more. However, construction risk parameters like inaccurate estimates and others are responsible for the development of internal risk events. After a thorough analysis of the literature, a risk impact event list was created, even though the literature did not shed light on cost overrun and risk event relationship which was investigated through models. The risk event relationship models can be efficiently presented through multiple regression procedures. This regression analysis technique is adequate and able to state the relationship between the independent and dependent variables using the observed behavior that is stated by the statistically measured relationships. Hence, regression models were developed using multiple regression analysis. These models helped to identify the classified risk event influence where the independent variable is cost overrun. The F-statistic (Sig.<0.01) "significance" value was presented using the ANOVA tests which indicate that the significance of the developed regression models is at a $99 \%$ confidence level. Hence, the results indicate that the developed models are acceptable. Even though the ANOVA tests proved to be useful for testing the developed model and its ability to analyze the variations present in risk event data, it is still not able to indicate the level of relationship among the proxy variable and risk events. Therefore, the coefficient of determination $\left(\mathrm{R}^{2}\right)$ is used to measure the relationship strength. It should be noted that the current research does not include several risk events that might influence the final results in other circumstances.

\section{CONCLUSION}

Cost overrun is mostly caused by uncertainties within the environment of a construction project. In the current research, analysis has been carried out upon the interdependency and association among risk constructs, exogenous risk constructs, and risk outcomes. The acquired multiple-regression equations state the relationship among risk constructs. The Monte Carlo simulation helps model the risk construct while keeping in mind its stochastic nature. According to the results, (Figures 3- 
4), $17 \mathrm{SR}$ is the cost with the minimum risk impact of 0.025 and $892 \mathrm{SR}$ is the cost with maximum risk impact of 0.776 . Further analysis must be carried out upon the relationship among exogenous and endogenous risk variables to help enhance the extraction of the risk impact amplification because of the active interdependency among system factors along with the output results and system input factors.

Many construction projects are completed over budget and over time. The presence of uncertainties, inherent in construction projects' environment, plays an essential role in construction cost overrun. This research has addressed the vital issue of interdependency between risk constructs and risk consequences. The interaction between the risk constructs is captured using multiple regression equations. The stochastic nature of the risk constructs was modeled. There is a need to further investigate the interaction between risk factors in order to increase the detection of any amplification of risk impacts due to the dynamic interdependency within system variables and between the system input variables and output outcomes.

\section{REFERENCES}

[1] M. A. Akhund, A. R. Khoso, A. A. Pathan, H. U. Imad, and F. Siddiqui, "Risk Attributes, Influencing the Time and Cost Overrun in Joint Venture Construction Projects of Pakistan," Engineering, Technology \& Applied Science Research, vol. 8, no. 4, pp. 3260-3264, Aug. 2018.

[2] N. J. Smith, T. Merna, and P. Jobling, Managing Risk in Construction Projects, 3rd ed. Hoboken, NJ, USA: Wiley-Blackwell, 2014.

[3] D. Cooper, S. Grey, G. Raymond, and P. Walker, Project Risk Management Guidelines: Managing Risk in Large Projects and Complex Procurements. Hoboken, NJ, USA: Wiley, 2005.

[4] D. A. Wehrung, K.-H. Lee, D. K. Tse, and I. B. Vertinsky, "Adjusting risky situations: A theoretical framework and empirical test," Journal of Risk and Uncertainty, vol. 2, no. 2, pp. 189-212, Jun. 1989, doi: 10.1007/BF00056137.

[5] M.-T. Wang and H.-Y. Chou, "Risk Allocation and Risk Handling of Highway Projects in Taiwan," Journal of Management in Engineering, vol. 19, no. 2, pp. 60-68, Apr. 2003, doi: 10.1061/(ASCE)0742597X(2003) 19:2(60).

[6] E. Witt, "Procurement Arrangements and Risk Transfer in construction projects - initial evidence from Estonia," presented at the Modern Building Materials, Structures and Techniques, Vilnius, Lithuania, May 2010 .

[7] P. T. Nguyen and P. C. Nguyen, "Risk Management in Engineering and Construction: A Case Study in Design-Build Projects in Vietnam," Engineering, Technology \& Applied Science Research, vol. 10, no. 1, pp. 5237-5241, Feb. 2020.

[8] I. A. Ansari, "Evaluating the financial robustness of special purpose vehicles involved in the delivery of defence private finance initiatives," Ph.D. dissertation, Cranfield University, 2014.

[9] S. S. Gao and M. Handley-Schachler, "Public bodies' perceptions on risk transfer in the UK's private finance initiative.," Journal of Finance and Management in Public Services, vol. 3, no. 1, pp. 25-39, 2003.

[10] T. Dixon, G. Pottinger, and A. Jordan, "Lessons from the private finance initiative in the UK: benefits, problems and critical success factors," Journal of Property Investment and Finance, vol. 23, no. 5, pp. 412423, 2005.

[11] M. P. Abednego and S. O. Ogunlana, "Good project governance for proper risk allocation in public-private partnerships in Indonesia," International Journal of Project Management, vol. 24, no. 7, pp. 622634, Oct. 2006, doi: 10.1016/j.ijproman.2006.07.010.

[12] A. Boussabaine, Risk Pricing Strategies for Public-Private Partnership Projects. Hoboken, NJ, USA: Wiley-Blackwell, 2013.
[13] D. J. Price, A. M. Pollock, and S. Player, "Public risk for private gain? The public audit implications of risk transfer and private finance." Public Health Policy Unit, School of Public Policy, UCL, London, 2004.

[14] A. D. Ibrahim, A. D. F. Price, and A. R. J. Dainty, "The analysis and allocation of risks in public private partnerships in infrastructure projects in Nigeria," Journal of Financial Management of Property and Construction, vol. 11, no. 3, pp. 149-164, Jan. 2006, doi: 10.1108/13664380680001086.

[15] A. Dziadosz, A. Tomczyk, and O. Kapliński, "Financial Risk Estimation in Construction Contracts," Procedia Engineering, vol. 122, pp. 120 128, Jan. 2015, doi: 10.1016/j.proeng.2015.10.015.

[16] A. Alfraidi, S. M. Alzahrani, F. Binsarra, M. H. H. Abdelhafez, E. M. Noaime, and M. A. S. Mohamed, "Impact of political risk on construction cost in PPP project in KSA," International Journal of Advanced and Applied Sciences, vol. 7, no. 5, pp. 6-11, May 2020, doi: 10.21833/ijaas.2020.05.002.

[17] F.-M. Liou and C.-P. Huang, "Automated Approach to Negotiations of BOT Contracts with the Consideration of Project Risk," Journal of Construction Engineering and Management, vol. 134, no. 1, pp. 18-24, Jan. 2008, doi: 10.1061/(ASCE)0733-9364(2008)134:1(18).

[18] J. S. Russel, "Decision models for analysis and evaluation of construction contractors," Construction Management and Economics, vol. 10, no. 3, pp. 185-202, Jul. 2006, doi: 10.1080/01446199200000018. 